\title{
INTELLECTUAL HUMiLity, TESTIMONY, AND EPISTEMic INJUSTICE
}

IAN M. CHURCH

In the typical case, when a person utters or testifies that a given proposition " $p$," the goal is for someone else to come to believe or know (given that $p$ is true) that $p$. Of course, this testimonial exchange can go wrong in many different ways, and various intellectual vices can contribute to this-including epistemic injustice and an absence of intellectual humility (i.e. intellectual arrogance or intellectual servility). The $21^{\text {st }}$ century has seen a "social turn" within epistemology, which has led to a growing amount of exciting research on the epistemology of testimony, peer disagreement, and the general social circumstances of human knowing. Additionally, for over 35 years, virtue epistemology has played a dominant role in the epistemological literature, which has more recently lead to a flurry of interest in particular intellectual virtues like intellectual humility and vices like epistemic injustice. And happily, more work is now being done connecting virtue-theory with this social turn in epistemology, including exciting work on group virtues (see Kallestrup forthcoming). And while this has led to some fruitful dialogue about the virtues and vices at play in the epistemology of testimony-including work exploring the relationship between epistemic injustice and testimony (see Peet 2017; McKinnon 2016; Tanesini 2016)—little work has yet been done exploring how virtues like intellectual humility (or its corresponding vices, intellectual arrogance or intellectual servility) might influence when and why we believe what others tell us or even contribute to vices like epistemic injustice.

To see how these issues might be connected, consider the following influential case from Miranda Fricker's Epistemic Injustice: Power and the Ethics of Knowing (2007):

It is the Fifties, and we are in Venice. Herbert Greenleaf, a rich American industrialist, is visiting, accompanied by a private detective whom he has hired to help solve the mystery of the whereabouts of his renegade son, Dickie. Dickie Greenleaf recently got engaged to his girlfriend, Marge Sherwood, but subsequently spent a great deal of time travelling with their 'friend' Tom Ripley-until Dickie mysteriously disappeared. Marge is increasingly distrustful of Ripley because he seems to be obsessed with Dickie and suspiciously bound up with his strange disappearance. She also knows very well that it is unlike Dickie-unreliable philanderer though he undoubtedly was-simply to do a bunk, let alone to commit suicide, which is the hypothesis that Ripley is at pains to encourage. Ripley, however, has all along done a successful job of sucking up to Greenleaf senior, so Marge is entirely alone in her suspicion—-her correct suspicion— that Dickie has been murdered, and that Ripley 
is his killer...Greenleaf is only too aware of how little he himself knows of his son...and yet he fails to see Marge as the source of knowledge about Dickie that she manifestly is. This attitude leads Greenleaf to ignore one of Marge's key reasons for her correct hypothesis that Dickie has died at the hands of Ripley: she finds Dickie's rings at Ripley's place, one of which had been a gift from her and which he had sworn never to remove. Greenleaf ignores it, partly because he underestimates Dickie's commitment to Marge, so that in his eyes any promise to Marge on Dickie's part is virtually worthless; but mostly because Ripley successfully constructs Marge as 'hysterical'. Indeed, not only Greenleaf but also Marge's friend, Peter Smith-Kingsley, comes to perceive her that way, so that the net result is a collusion of men against Marge's word being taken seriously. The theme of knowledge ever to the fore in the dialogue, we at one point hear her off-screen, shortly after she finds the rings, her powers of expression seemingly reduced to a self-contradictory mantra, repeating emphatically to the incredulous Greenleaf, 'I don't know, I don't know, I just know it'; and it is at this point that Greenleaf replies with the familiar put-down, 'Marge, there’s female intuition, and then there are facts—.'1 (2007, pp. 86-88)

Herbert Greenleaf wants to know what happened to his son, Dickie; after all, that's why he came to Venice and hired a private detective. Marge knows what happened to Dickie, and she is more than happy to tell Greenleaf; however, he won't listen. Greenleaf doesn't value Marge's testimony, and subsequently fails to recognize valuable information. As Miranda Fricker unpacks this story, Greenleaf is guilty of committing epistemic injustice against Marge. According to Fricker, Greenleaf has wronged Marge "in [her] capacity as a giver of knowledge" (2007, p. 7).

This seems exactly right, but we might wonder if there is another vice lurking in the conceptual neighborhood. Perhaps we could also easily think of Greenleaf as guilty of intellectual arrogance. In snubbing Marge's testimony, perhaps Greenleaf is unjustifiably assuming that his cognitive faculties are better positioned or equipped than Marge's. And he attributes far more positive epistemic status to his beliefs regarding his son than is actually merited. But, then again, maybe we could also easily think of Greenleaf as guilty of intellectual servility. Despite Dickie's treasured rings being found at Ripley's place, Greenleaf doesn't attribute nearly the positive epistemic status to the belief that Ripley could be the killer that he should. And, again and again, Greenleaf simply does not track the positive epistemic status of the valuable information that Marge offers him.

In this exploratory paper, I want to consider how intellectual humility and epistemic injustice might contribute to the failure of testimonial exchanges. In $\$ 1$, I will briefly highlight four broad ways a testimonial exchange might fail. In $\$ 2$, I will very briefly review the nature of epistemic injustice. In $₫ 3$, I will explore how both epistemic injustice and intellectual humility can lead to

1 Minghella 2000, p. 130. 
failures in testimonial exchange, and I'll conclude by suggesting how intellectual humility and epistemic injustice might be related.

But what is intellectual humility? One account of this virtue is the doxastic account of intellectual humility, according to which intellectual humility is the virtue of accurately tracking what one could non-culpably take to be the positive epistemic status of one's own beliefs. On this view, intellectual arrogance would be the vice of overestimating the positive epistemic status of one's beliefs, and intellectual servility would be the vice of underestimating the positive epistemic status of one's beliefs. This is a view I have defended elsewhere (see, for example Church 2016; Church and Samuelson 2017), and I won't repeat myself here. But, to be sure, there are plenty of other accounts in the literature. For example, in their seminal account, Bob Roberts and Jay Wood (2007, 2003) defined intellectual humility as having a low concern for status when pursing various intellectual goals. Dennis Whitcomb, Heather Battaly, Jason Baehr, and Daniel Howard-Snyder (2015) have argued that intellectual humility is the virtue of attending to and owning one's intellectual limitations. More recently, Alessandra Tanesini has argued that intellectual humility is "a cluster of strong attitudes (as these are understood in social psychology) directed toward one's cognitive make-up and its components, together with the cognitive and affective states that constitute their contents or bases, which serve knowledge and value-expressive functions” (2018, p. 399). All that said, however, we don't need to worry too much about the exact definition of intellectual humility here; while I will occasionally draw from or reference my favored account of intellectual humility (the doxastic account), what I say in this chapter won't hinge too much on that particular account. I'm happy to work from a general and intuitive grasp of what intellectual humility might be. I'm hoping that most of what I say in this chapter will apply regardless of how we ultimately define intellectual humility.

\section{\$1: How Testimonial Exchanges can Fail}

Before we explore how testimony can go wrong, we should consider the basic anatomy of a testimonial exchange. For Jonathan Adler (2012), the core cases of testimonial exchange involve two strangers (with no prior engagement with each other)—one person giving the testimony (let's call this person SPEAKER) and another person receiving the testimony (let's call this person HEARER). SPEAKER's testimony involves a single assertion, $p$, and SPEAKER's testimony is solely responsible for sustaining HEARER's belief that $p$. And finally, the context of the testimony is 
one where there is a shared norm of truth-telling and where there are no unusual professional or institutional demands for accuracy. In sum, when we're considering the general ways that a testimonial exchange might fail, it is important that we try to think about testimonial exchanges in their most basic form; testimonial exchanges where we have one speaker making a single assertion, $p$, to a single hearer.

Now we can begin to see specific ways testimonial exchanges can go wrong. Assuming that the goal of testimony is for a given hearer to acquire knowledge through the utterance of a given speaker, testimonial exchanges go wrong whenever the hearer does not acquire knowledge from the speaker's utterance. ${ }^{2}$ With the basic anatomy of testimony noted above, I think we can highlight four general areas where testimony can go wrong: (i) with the hearer, (ii) with the speaker, (iii) with the utterance " $p$ ", and (iv) with the general environment. Let's now consider an example of each.

Obviously enough, if there are significant problems with a given hearer-if for example, the hearer is severely inebriated-then the hearer won't be able to acquire knowledge from speaker's utterance that $p$. Consider the following case:

BAD HEARER: HEARER is visiting Chicago. While walking down the street, she sees SPEAKER, an ostensibly normal looking stranger, and asks for directions to the Willis Tower. SPEAKER gives HEARER what sounds like plausible directions. However, given that HEARER is deeply confused about the major skyscrapers in Chicago_-for example, regularly confusing the Willis tower with the Trump tower-it is not clear that HEARER knows how to get to the Willis Tower, since it is unclear whether or not HEARER actually knows what building "Willis Tower" refers to.

Given HEARER's deep confusion about Chicago skyscrapers, when she asks for directions to the Willis Tower we might wonder whether or not she is really looking for the Willis Tower. And even if SPEAKER gives HEARER flawless, clear and precise directions, it's not clear that she can acquire knowledge from these directions because she is so very confused about what buildings are what in downtown Chicago.

\footnotetext{
2 To be sure, testimony can go wrong in all sorts of ways not captured by the basic model of testimonial exchange sketched above. For example, speakers rarely go around making utterances unprompted; as such, hearers often have to initiate the testimonial exchange by asking a question. And if their question is itself confusing or poorly articulated, then that can also pose a serious hurdle to a successful testimonial exchange. For the sake of space, however, we'll leave such complicating factors to the side and stick to the aforementioned basic model.
} 
Additionally, if there are significant problems with a given speaker-if, for example, a given speaker is severely intoxicated or otherwise rendered sufficiently unreliable- then anyone who hears speaker's testimony will be unable to acquire knowledge from it. Consider another case:

BAD SPEAKER: HEARER is visiting Chicago, and wants to visit the Willis Tower. While walking down the street, she sees SPEAKER, an ostensibly normal looking stranger, and asks for directions. SPEAKER gives HEARER what sounds like plausible directions; however, SPEAKER is deeply confused about the names of Chicago skyscrapers-regularly, for example, confusing the Willis Tower for the Trump Tower. As such, it is not at all clear that HEARER can know how to get to the Willis Tower from SPEAKER's testimony, because there is a real chance that SPEAKER is confusing the Willis Tower with the Trump Tower.

Given SPEAKER's deep confusion about Chicago skyscrapers in BAD SPEAKER, any testimony about those skyscrapers-including testimony regarding how to get to them-seems undermined. SPEAKER, in this case, is not a reliable source of testimonial knowledge about Chicago skyscrapers. Naturally enough, another way that a given testimonial exchange can go wrong is if the testimony, the assertion itself, is a bad one. Consider another case:

BAD ASSERTION: HEARER is visiting Chicago, and wants to visit the Willis Tower. While walking down the street, she sees SPEAKER, an ostensibly normal looking stranger, and asks for directions. SPEAKER gives HEARER what sounds like plausible directions. On this occasion, however, SPEAKER — who is normally a very reliable and helpful giver of directions - decides to sow some chaos in the world and give HEARER directions to the town dump instead of directions to the Willis Tower.

Given that SPEAKER gives HEARER false information regarding the location of the Willis Tower, HEARER simply cannot acquire knowledge as to how to find the Willis Tower from SPEAKER's testimony. Speaking falsehoods, obviously enough, undermines the transferal of knowledge, given that knowledge that $p$ requires that $p$ be true.

How can an environment inhibit the acquisition of knowledge in a standard case of testimonial exchange? Consider the following case:

BAD ENVIRONMENT: HEARER is visiting Chicago, and wants to visit the Willis Tower. While walking down the street, she sees SPEAKER, an ostensibly normal looking stranger, and asks for directions. Unbeknownst to HEARER, however, nine out of ten Chicagoans are deeply put off by the Sears Tower's name being changed to the Willis Tower. So much so, in fact, that if asked for directions to the "Willis Tower," nine out of ten Chicagoans will actually give directions to the town dump in protest. SPEAKER, as it happens, is not one of 
those Chicagoans who is put off by the name change; so when SPEAKER is asked for directions to the Willis Tower, she reliably gives directions to the Willis Tower.

There's nothing wrong with HEARER or SPEAKER in BAD ENVIRONMENT. And SPEAKER gives good testimony, she gives HEARER good directions to the Willis Tower. Why should we be hesitant to grant HEARER knowledge in this case? Because, like the protagonist's belief in FAKE BARN cases, her correct belief (regarding the location of the Willis Tower) is extremely lucky. She could have very easily asked any of the other Chicagoans on the street, the majority of which would have given her directions to the town dump instead of the Tower.

\section{\$2: Testimonial Injustice}

In general, epistemic injustice occurs when "a wrong is done to someone specifically in their capacity as a knower." (Fricker 2007, p. 1). And this can occur in all sorts of ways. As Katherine Hawley notes, "[p]erhaps the most obvious type of epistemic injustice occurs when people are unfairly prevented from obtaining knowledge because of their lack of access to education, resources, or social networks.” (2011, p. 283). In Miranda Fricker's landmark book, Epistemic Injustice (2007), she identifies two kinds of epistemic injustice: hermeneutical injustice and testimonial injustice. Hermeneutical injustice involves "structural prejudice in the economy of collective hermeneutical resources” (2007, p. 1). As Heidi Grasswick helpfully explains:

Hermeneutical injustice occurs when there exists a lack of collective interpretative resources required for a group to understand (and express) significant aspects of their social experience. Fricker offers the example of the situation of women who experienced episodes of what we now identify as sexual harassment, prior to it being named and recognized as such. Without the presence of a socially recognized concept of sexual harassment, women were ill-equipped to both understand and convey these significant experiences and their harms. (2013, sec. 4.1)

While hermeneutical epistemic injustice is, no doubt, a useful and revealing concept-being incredibly useful in feminist approaches to epistemology, for example — the kind of epistemic injustice we're most interested in this chapter is testimonial injustice.

Testimonial injustice occurs when a person or group is not given the credibility that they deserve. Or, as Fricker puts it, testimonial injustice occurs when "someone is wronged in their 
capacity as a giver of knowledge" (Fricker 2007, p. 7, emphasis mine). In the typical case, this means giving a person or group less credibility than they deserve. For an example of this kind of epistemic injustice, think about Greenleaf's distrust of Marge's testimony in the case at the start of this paper. And some scholars simply define testimonial injustice merely along these lines. ${ }^{3}$ However, we might also think that an epistemic injustice occurs when a person or group is given more credibility than they deserve. ${ }^{4}$ Going back to the Greenleaf example, Greenleaf arguably trusts Ripley far more than he deserves simply because he's a man, which can be seen as a type of testimonial injustice as well. Is Ripley "wronged in his capacity as a knower" if he is given far more credibility than he deserves? Maybe. (Though our intuitions might be clouded in this case by the fact that Ripley is a murderer.) If so, then this is indeed another (perhaps surprising) example of testimonial injustice. But, even if Ripley isn't "wronged in his capacity as a knower" this is nevertheless something very closely related to testimonial injustice.

\section{\$3: Epistemic Injustice and Intellectual Humility and Failures in Testimonial Exchange}

Now, clearly enough, some failures in testimonial exchange give rise to epistemic injustice, in particular testimonial injustice. Greenleaf wanted to know who his son's killer was, and Marge's testimony could have told him this; however, Greenleaf doesn't believe her testimony. And as we noted at the start of this paper, we might plausibly think that a lack of intellectual humility is at work here too. After all, Greenleaf certainly seems intellectually arrogant in his disregard of Marge's testimony. In this section, I now want to say a bit more about how these things—-testimonial failure, epistemic injustice, and intellectual humility_-might all hang together.

The first thing to note is that testimonial injustice only arises from failures in testimonial exchange where there is something wrong with the hearer. Again, to quote Fricker, testimonial injustice occurs when "someone is wronged in their capacity as a giver of knowledge" (Fricker 2007, p. 7). As such, we might think of testimonial injustice in terms of not giving a person or group the credibility that they deserve-in particular, when they are giving testimony. Of course, that's not to say that all failures in testimonial exchange give rise to testimonial injustice-the case BAD HEARER certainly doesn't manifest testimonial injustice-however, whenever we have a case of testimonial injustice it is going to be a

\footnotetext{
${ }^{3}$ For example, Heidi Grasswick identifies testimonial injustice as occurring "when a speaker is given less credibility than deserved (suffering a credibility deficit) because of an identity prejudice held by the hearer." (2013, sec. 4.1).

${ }_{4}^{4}$ Medina 2011 explores this possibility further. Also see Coady 2017.
} 
case where a testimonial exchange has failed as a result of there being something wrong (viciously wrong) with the hearer. ${ }^{5}$

But importantly, it's not just testimonial injustice that is relevant to testimony, to how testimony might fail. Instead of being a product of a failure of testimonial exchange, other types of epistemic injustice (like hermeneutical injustice) can give rise to failures of testimonial exchange. Consider a failure of testimonial exchange where something has gone wrong with the hearer. Imagine a culture where the intellectual accomplishments or achievements of women are never celebrated or even acknowledged; instead women are routinely dismissed as un-intellectual. In such a context, a woman might ask a question about Gödel's incompleteness theorem, be given a good and true answers, and yet nevertheless fail to believe what she has been told because she's convinced herself that she can't understand such things. ${ }^{6}$ Notice, this isn't an example of testimonial injustice, because she's giving the testifier the creditability they deserve; nevertheless, it's still an example of epistemic injustice. And in this case, instead of the failure of testimonial exchange giving rise to the epistemic injustice, it is the epistemic injustice that leads to the failure in testimonial exchange.

Non-testimonial forms epistemic injustice can lead to other types of failures in testimonial exchange. Consider a failure of testimonial exchange where something has gone wrong with the speaker. Again, imagine a culture where the intellectual accomplishments or achievements of women are never celebrated or even acknowledged; instead women are routinely dismissed as un-intellectual. In such a context, a woman might feel extremely sheepish about sharing an insight, or giving testimony without caveating everything she says by hedging her claims and being self-deprecating. An outsider to this culture (who doesn't share this negative view of women) might happily ask a woman for directions, but not ultimately believe what she says because of all of the hedging and self-deprecating remarks. In this situation, it's the negative attitudes toward the intellectual contributions of women that is the epistemic injustice (though not an example of testimonial injustice), and this is what can give rise to the failure of testimonial exchange.

Consider a failure of testimonial exchange where the problem lies primarily in the environment. Imagine a culture where men routinely refrain from sharing truths with womenperhaps thinking that the truth can really only be properly handled and disseminated by men to men.

\footnotetext{
5 This isn't to say that a testimonial exchange cannot fail due to a vice in the hearer that is unrelated to testimonial injustice. A testifier's membership in a stigmatized group might contribute to a failure of testimonial exchange in such a way that isn't an example of testimonial injustice. The claim that is being made here, however, is that whenever there is an example of testimonial injustice then there is necessarily something wrong (in the sense explored in \$1) with the hearer.

${ }^{6}$ For more on phenomena like this, see Dotson 2011, 2014
} 
Because of this, let's imagine that the vast majority of men in this environment, would lie to a woman if they were asked for even basic truths (like directions). And imagine a woman from outside of this culture (who doesn't know about the "no sharing truths with women" rule) asks a man for directions. And let's say that this man is the exception to the rule in this culture, such that he is one of the very few men who doesn't mind sharing truths with everyone. And let's say he gives the outsider woman good, true directions to where she wants to go. Does she know how to get where she wants to go? If we think that the kind of environmental luck we find in Fake Barn-style cases precludes knowledge, then we'd have to say, "no," she doesn't know where she's going because she could have too easily gotten bad directions from one of the other men in the local environment. Again, in this situation, it's the negative attitudes toward sharing truth with women that is the epistemic injustice (though not an example of testimonial injustice), and this is what can give rise to the failure of testimonial exchange.

The only kind of failure in testimonial exchange where it's not easy to see how epistemic injustice could cause such a failure is a failure in testimonial exchange where there is something wrong with the utterance. However, that's understandable. In talking about epistemic injustice (or intellectual humility, for that matter), we're typically talking about intellectual character traits (virtues or vices); as such, if there is an instance of epistemic injustice that we'd want to point to as leading to a bad utterance, we'd be more inclined attribute this vice to a person (be it the hearer, the speaker, or people in the environment) and not to the utterance itself. Epistemic virtue and vice are best applied to epistemic agents and not utterances.

And clearly enough, like non-testimonial epistemic injustice, a lack of intellectual humility can also lead to a given testimonial exchange failing to transmit knowledge. Of course, intellectual humility doesn't guarantee that testimony will work as it should. For example, someone can be perfectly intellectually humble and still be lied to, or someone can be perfectly intellectually humble and still find themselves in environments hostile to knowledge acquisition via testimony. And what is more, intellectual vice_-namely, intellectual arrogance or intellectual servility — are not any guarantee that testimony will fail. Someone can be a complete, arrogant jerk and still acquire knowledge via testimony. Someone can be intellectually servile and self-deprecating and still acquire knowledge via testimony. But in any case, someone who fails to be intellectually humble might very well be more susceptible to failures in testimonial exchange than, everything else being the same, someone who doesn't, someone who is intellectually humble. 
Consider the Greenleaf case again. The first place we noted where testimonial exchanges could fail is with the hearer-with the person receiving the testimony. It is Greenleaf, the hearer, who fails to listen to the excellent testimony of Marge, and it is Greenleaf, the hearer, who listens unreflectively to the lies and deceptions of Ricky. But if we draw from the doxastic account of intellectual humility-where intellectual humility is the virtue of accurately tracking what one could non-culpably take to be the positive epistemic status of one's own beliefs-we can easily think of the failure in Greenleaf as a failure in intellectual bumility. After all, Greenleaf is simply not accurately tracking what he could non-culpably take to be the positive epistemic status of his belief regarding his son-the belief which of central importance to the case. Greenleaf is intellectual arrogant in holding his belief regarding the lack of value of Marge's testimony and the value of Ricky's as strongly as he does. And, ultimately, Greenleaf is intellectually arrogant in holding his belief regarding his son's fate as strong as he does, because he has systematically (and out of prejudice) failed to track defeaters for his belief (presented by Marge). ${ }^{7}$

And to be sure, this result doesn't rest on the doxastic account of intellectual humility; other accounts of intellectual humility could come to a similar verdict. Take Roberts and Wood's account of intellectual humility where intellectual humility is "a striking or unusual unconcern for social importance, and thus a kind of emotional insensitivity to the issues of status" when it comes to acquiring epistemic goods (2007, p. 239). Greenleaf, I think we can agree, is simply not sufficiently insensitive to issues of status when it comes to pursuing epistemic resources regarding his son's fate. In particular, Greenleaf seems hypersensitive to his and Ripley's status as men over and against Marge's status as a woman. So again, it looks like we could say that Greenleaf's failure at intellectual humility fed his prejudice and ultimately lead to a testimonial injustice.

And we can also think of cases where a lack of intellectual humility in the speaker or a lack of intellectual humility in the local environment can also lead to failures in testimonial exchanges.

\footnotetext{
${ }^{7}$ Of course, the testimony in the case of Greenleaf's search for his son fails for lots of reasons. Like the BAD ASSERTION case, Ricky's lie helps preclude viable testimonial exchange. And perhaps we could make the case that there was something wrong with the environment Greenleaf found himself in (like the BAD ENVIRONMENT case), an environment with a critical mass of liars and co-conspirators of gender prejudice. But it is worth stressing that had Greenleaf been more intellectually humble_-had he done a better job accurately tracking the positive epistemic status of his beliefs (specifically his belief regarding the fate of his son and his belief regarding the value of Marge's testimony), these other treats to testimonial exchange might have been mitigated or otherwise assuaged. If Greenleaf had been a better, more intellectually humble HEARER, then maybe he could have recognized Ricky's bad assertion (or later recognized he had defeaters for Ricky's assertion that he needed to address). And maybe if Greenleaf had been a better, more intellectually humble HEARER, he could have recognized the poor quality of his environment and taken extra precautions. Greenleaf's failure, I propose, to accurately track the epistemic value of women's testimony (including the testimony of Marge) fed his prejudice and lead to not only a failure in testimonial exchange but also to epistemic injustice.
} 
We can think of cases where a given speaker is so intellectually servile that their testimony seems understandably untrustworthy to reflective hearers. Or we can imagine an environment where 9 out of 10 people would give misinformation because they're far too confident in what they know. However, like non-testimonial epistemic injustice, the only kind of failure in testimonial exchange where it's not easy to see how a lack of intellectual humility could cause such a failure is a failure in testimonial exchange where there is something wrong with the utterance. But, again, I think this makes sense given that the proper objects of intellectual humility and its corresponding vices are agents (hearers or speakers) and not utterances.

Importantly, however, failures in testimony as a result of non-testimonial epistemic injustice don't seem to be necessarily linked in any way with failures of intellectual humility. It seems as though we can imagine cases where everyone in the local environment is intellectually humble, but where certain members of that environment simply don't have access to important epistemic resources. Or we can imagine cases where someone is afflicted with anxiety and imposters syndrome such that they become self-doubting and intellectually servile; this might lead to failures in testimonial exchange, but without being the product of any non-testimonial epistemic injustice.

Testimonial injustice, however, might be different. It seems like testimonial injustice might be necessarily linked with failures of intellectual humility. To be sure, someone can fail to be intellectually humble without committing testimonial injustice (just imagine an intellectually arrogant person sitting alone on a deserted island); however, all cases of testimonial injustice-where someone doesn't give someone else the credibility that they deserve-could potentially be seen as a product of either intellectual arrogance of intellectual servility. ${ }^{8}$ Consider again Roberts and Wood's account of intellectual humility in term of "a striking or unusual unconcern for social importance, and thus a kind of emotional insensitivity to the issues of status" when it comes to acquiring epistemic goods (2007, p. 239). If testimonial injustice quintessentially involves a reliance on stereotypes concerning a stigmatized group, then perhaps this necessarily signals the kind of concern (or even hyper-concern) for social status or issues of status that Roberts and Wood see as incompatible with intellectual humility. But the connection between testimonial injustice and intellectual humility is particularly easy to see within the doxastic account of intellectual humility: if testimonial injustice consists of not giving someone the credibility that they deserve, then we might think that every instance of

\footnotetext{
${ }^{8}$ Intuitions might diverge here according to how we want to ultimately define intellectual humility. For the sake of this paper, we'll need to put debates concerning the definition of intellectual to the side; however, I hope that the above considerations show how at least a few of the proposed definition in the contemporary literature seem to point to this connection between intellectual humility and testimonial injustice.
} 
testimonial injustice is an instances where someone is not accurately tracking the positive epistemic status of their beliefs (because they've failed to accurately account for the epistemic value of the relevant testimony).

\section{Conclusion}

As epistemology continues to go through its "social turn" and as more and more work is done on intellectual virtues and vices, it's worth considering how these issues might be related. In this exploratory paper, I tried to suggest some ways failures in testimonial exchanges might be produced by epistemic injustice or a lack of intellectual humility. In the end, we were able to see that even non-testimonial variants of epistemic injustice are relevant to testimony and can cause failures in testimonial exchange in a number of different ways. Testimonial injustice, in contrast, doesn't cause failures in testimonial exchange, but is instead the product of a particular kind of failure, namely, failures in testimonial exchanges where the problem lies with the hearer. Vices like intellectual arrogance or intellectual servility can lead to failures in testimonial exchange as well. And while these failures are largely independent from epistemic injustice, some forms of epistemic injustice (namely, testimonial injustice) might be intimately connected with a lack of intellectual humility. There is, no doubt, a lot more to say on these issues, but hopefully these preliminary remarks can be useful for future research in these areas.

\section{References:}

Adler, J. (2012). Epistemological Problems of Testimony. The Stanford Encyclopedia of Philosophy, http://plato.stanford.edu/archives/sum2015/entriesestimony-episprob/.

Church, I. M. (2016). The Doxastic Account of Intellectual Humility. Logos \& Episteme, 7(4), pp. 413-33.

Church, I. M, and Samuelson, P. L. (2017). Intellectual Humility: An Introduction to the Philosophy and Science. New York: Bloomsbury Academic.

\footnotetext{
${ }^{9}$ I am enormously thankful to Alessandra Tanesini for her comments and apt criticism of an earlier draft of this chapter. This research was supported in part by a grant from the John Templeton Foundation.
} 
Coady, D. (2017). Epistemic Injustice as Distributive Injustice. In I. Kidd, J. Medina, and G. Pohlhaus Jr. eds. The Routledge Handbook of Epistemic Injustice. New York, NY: Routledge, pp. 61-68.

Dotson, K. (2011). Tracking Epistemic Violence, Tracking Practices of Silencing. Hypatia, 26(2), pp. $236-257$.

Dotson, K. (2014). Conceptualizing Epistemic Oppression. Social Epistemology, 28(2), pp. 115-138.

Fricker, M. (2007). Epistemic Injustice: Power and the Ethics of Knowing. New York: OUP Oxford.

Grasswick, H. (2013). Feminist Social Epistemology. The Stanford Encyclopedia of Philosophy. https://plato.stanford.edu/archives/win2016/entries/feminist-social-epistemology/.

Hawley, K. (2011). Knowing How and Epistemic Injustice. In J. Bengson and M. A. Moffett. eds.Knowing How: Essays on Knowledge, Mind, and Action. New York: Oxford University Press, pp. 283-99.

Kallestrup, J. (forthcoming). Group Virtue Epistemology. Synthese, pp. 1-19.

McKinnon, R. (2016). Epistemic Injustice. Philosophy Compass, 11(8), pp. 437-446.

Medina, J. (2011). The Relevance of Credibility Excess in a Proportional View of Epistemic Injustice: Differential Epistemic Authority and the Social Imaginary. Social Epistemology, 25(1), pp. 15-35.

Minghella, A. (2000). The Talented Mr Ripley: Based on Patricia Highsmith's Novel. London: Methuen.

Peet, A. (2017). Epistemic Injustice in Utterance Interpretation. Synthese, 194(9), pp. 3421-3443.

Roberts, R C., and Wood, W. J. (2003). Humility and Epistemic Goods. In Intellectual Virtue: Perspectives From Ethics and Epistemology. Oxford: Oxford University Press, pp. 257-79.

Roberts, R C., and Wood, W. J. (2007). Intellectual Virtues: An Essay in Regulative Epistemology. Oxford: Clarendon Press.

Tanesini, A. (2016). 'Calm Down, Dear': Intellectual Arrogance, Silencing and Ignorance. Aristotelian Society Supplementary Volume, 90(1), pp. 71-92.

Tanesini, A. (2018). Intellectual Humility as Attitude. Philosophy and Phenomenological Research, 96(2), pp. 399-420.

Whitcomb, D, Battaly, H., Baehr, and J. and Howard-Snyder, D. (2015). Intellectual Humility: Owning Our Limitations. Philosophy and Phenomenological Research, 91 (1): pp. 1-31. 